\title{
Code Mixing among Tamil - English Bilingual Children
}

\author{
Kanthimathi Krishnasamy
}

\begin{abstract}
A bilingual's repertoire consists of two or more languages or codes and bilingual's mix the codes in the course of conversation. In India, where English is a language of prestige, code mixing with English symbolizes higher status. Does only the prestige status of English make children use English while speaking in their mother tongue? What are the reasons of code mixing among children then? This study describes the nature of language behavior of Tamil-English bilingual children. This study throws light on the direction in which language change is taking place.
\end{abstract}

Index Terms - Code mixing, bilingual children, language purity, tamil-English mixing.

\section{INTRODUCTION}

Code mixing English with mother tongue has become a regular practice among bilinguals. This phenomenon is largely observed amongst educated people though not absolutely absent amongst less educated and uneducated. Code mixing with English by Tamils has been evidenced in numerous fields: television, radio, college, business etc. Exposure to English from various sources has been one of the major reasons for code mixing with English. Mixing mother tongue and English is observed among kids too. Early exposure to English makes them bilingual from an early age. They also start mixing the two languages at an early age. This research paper tries to examine the speech of children in the age group 7-12 and answer the following questions:

1) What are the factors for code mixing among children?

2) Do children raised in bilingual setting code mix more?

3) What is the extent of mixing English in a Tamil conversation by children?

This research will provide information on Tamil-English code mixing by children in Tamilnadu.

Earlier research on bilingual code mixing among youngsters has shown that the younger generation code mixes for reasons like - easy to pronounce, to gain fluency in English, English words understood better, don't know Tamil equivalents, easy to express in English than in Tamil, prestigious to use English, modern and lack of Tamil equivalents [1]. This study looks into the code mixing pattern of children and the reasons for which they code mix. It will also throw light on the direction in which language change is taking place.

Language mixing is an advanced form of bilingual communication [2]. Bilingual individuals can modulate at any given moment, falling along a continuum of language modes that ranges from a monolingual language mode to a

Manuscript received May 3, 2014; revised July 6, 2014.

Kanthimathi Krishnasamy is with the Department of English, SDNB Vaishnav College for Women, Chennai, India (e-mail: kanthi.english@gmail.com). bilingual language mode. Language mixing is a behavior that is characteristic of the bilingual language mode [3]. Parents' bilingual language mode with the children must definitely influence the language behavior of the children. Chaudhary claims that knowledge of language(s) is stored together in the multilingual mind and the presence of multiple language features in a mind creates a mixed pattern of speech [4].

\section{LITERATURE REVIEW}

Studies on language acquisition confirm that knowledge of language is acquired and human mind can process multiple variations within a language. Language is a mental knowledge that is biologically predisposed to humans. This knowledge is universal because every language has same underlying formatives and rules. Once the universal formatives and rules are fixed, then it is believed that children can acquire any variations within and across languages. Humans are not specifically predisposed to acquire whatever human language is presented to them in childhood [5].

Children can acquire any language at any time. They can learn more than one language at a time. They can communicate with ease within and across language. Children can access more than two languages data simultaneously through the acquisition process. Empirical findings suggest that children are used to two different language words within an expression simultaneously. They don't face any obstacle to communicate their message by using the words from the two languages within an utterance.

Major [6] reports that, a child acquires the phonetic forms of words of two different languages independently. In the Indian context, especially in cities, where children grow up with two languages, there is simultaneous acquisition of two languages.

Children brought up in bilingual environment will be 'dominant' in one language or the other, sometimes variably at different stages of development, depending in part on the language environments in which they spend their time, but also on their individual preferences [7].

Studies have also shown that person's degree of bilingualism or proficiency in the two languages can change, even have a complete shift to one language forgetting the other based on the needs of the communication. Though there is no dearth of multilingual data in India, not many studies discuss children's language acquisition.

\section{Methodology}

The main focus of studies on code mixing has been on informal spoken interaction. Hence, data for this research was mainly taken from informal speech interactions between children. Spontaneous speech samples of sixty bilingual 
Tamil-English speaking children were recorded. Questionnaires were administered to the parents asking about the child's language behavior. And observation played a major role in understanding, supporting and proving the hypothesis of this research.

The children are described as bilingual as they have knowledge of the two languages fairly well. The children have been learning English from early years of school. They cannot be considered as balanced bilinguals.

Parents were asked to report about the child's language behavior. The contexts in which the children used mixed language were taken note of from the questionnaires. The children's source of exposure to English was also asked to be reported by the parents. Parents completed a one-page questionnaire, which asked them to answer all questions with respect to their language behavior during interactions with their child, the type of environment in which children received this exposure, parents were asked about their mixing of English with Tamil. Not all parents in the study were comfortable speaking in English. Some parents reported speaking both languages to their child at least some of the time.

Parents' responses to the questions on the Language Mixing Scale indicated how often they produced various types of language mixing in interactions with their child. Most parents reported regular language mixing in interactions with their children. Bilingual parents spend more time in a bilingual language mode and thus reported most language mixing.

\section{A. Data Recording - Picture Identifying Task and Story-Telling Task}

Children were asked to identify pictures shown to them from picture books. The pictures were randomly chosen from alphabet books in Tamil and English. The utterances of the children were recorded in a tape recorder and also noted down in a diary. Children were asked to narrate a story that they remembered. The students narrated the story in Tamil with the smattering use of English wherever they felt comfortable. The use of English was not deliberate but spontaneous. The recorded data was transcribed to check the patterns of code mixing and the extent in which English words were used.

\section{B. Picture Identifying Task}

It was observed that the children gave the names of the pictures in the language that they remembered very well. For e.g. Means of transportations like bus, train and boat they preferred to say in English rather in Tamil. Some of the Tamil medium students were able to give the Tamil names of the above mentioned means of transportation when asked to say in Tamil. The language which is frequently used and retrieved is used in speech often.

Children seemed to remember the names of the pictures in the language they learnt. The first utterances of the children were preferred as that was an instantaneous and spontaneous response. Picture book had images of animals, birds, flowers, things of daily use etc. Children remembered the English names of the pictures that they had learnt in their English books. For some pictures they gave Tamil names, but that was because those words were frequently used in Tamil at home or in their daily conversations. For Example: Lion, parrot, nest etc the children said in English. Whereas, for some pictures they instantly uttered Tamil names such as

- Ee -housefly

- ammikal - a stone to grind

- yakam- an oblation

- vazhai pazham -banana

The frequency of use of English makes this mental dictionary more accessible, as bilinguals whose mother tongue is Tamil obtain most of the formal education in English. Many everyday interactions involve English. As a result, words and concepts in English become more readily accessible than words in Tamil. There is a difference and delay in accessing and retrieving some words, as they are not frequently used [8]. The quantity of language input also determines the children's vocabulary knowledge [9].

\section{Story Telling Task}

The children were shown a story in picture. The story used was the popular and familiar 'Hare and the Tortoise story'. The children were excited on seeing a familiar story and started narrating enthusiastically. The narration was recorded. The children narrated the story in a mixed language with ease. There was no pause or hitch at the points where they changed codes. The language switch was smooth and effortless.

\section{Sample Story Narration by 7 Year Old - Hare and the Tortoise}

Children were asked to narrate a story that they remembered. Children narrated stories that they had heard and learnt in their childhood. Stories like that of the Hare and the Tortoise, the Sour Grapes, the Cunning Fox, Granny on the moon, the Thirsty crow etc. were narrated by the students.

Orunaal oru tortoiseum oru rabbitum race vaikalamnu sollichan. Race start pannanga. Rabbit fasta odichu. Tortoise slowva nadanthuchu. Appuram rabbit think pannichu tortoise slowvathaanavaruthunu tree keela thungalaamnu pochu. Tortoise slowva nadanthu nadanthu finish point reach aayiduchu. Rabbit thungi yendrichu paathu lateaa vanduchu. Tortoise first vanduchu.

The children were also asked to state about their preferred television programmes and the language in which they preferred to watch. Some of the programmes watched by children profusely use English in Tamil conversations. Programmes such as, Dora The explorer, Keymonache, Go Diego Go, Shin Chan etc use English in their regional language programmes. Apart from these many other television shows and advertisements also profusely use English in their programmes.

\section{OBSERVATIONS}

The primary school stage is the age when children start becoming bilinguals. The schools in Tamilnadu offer Tamil and English as medium of instruction. However the children are exposed to English from their Kindergarten. The mushrooming growth of the kindergartens and play- schools bring English to the children at a very early age (3 years). These schools have risen in popularity as the curriculum 
emphasizes more on familiarizing the children to English through activities. By the time the children enter school at the age of 5 they are quite familiar with the English language. English is taught as a compulsory subject in Tamil medium schools from classes 1 to 12. For the students in English medium schools most of the subjects are taught in English.

The children respondents chosen were from Tamil medium and English medium schools. The students were well versed in their mother tongue. The fluency of English differed. The students start becoming bilingual from the early age of 3 . In conversations the students from English medium were found extensively mixing with English. Tamil is the language that they predominantly speak at home. But this is slightly different in the case of students who come from urban elite and highly educated background. Some children get exposed to English even at home while conversing with family members. So Tamil and English start to coexist in the speech practice of the children from a very early age. The level of mixing of students from Tamil medium was comparatively lesser than those from English medium. It was also observed that Tamil predominated in families of the Tamil medium children. The parents of students from Tamil medium were not highly educated.

\section{A. Levels of Mixing}

Code mixing occurs at the lexical and phonological level. Instances of language mixing were delineated by analyzing the data for different levels of language mixing using the classification of Perecman [10]. Mixing at morphological and syntactic levels were also found. But they are not discussed in this paper.

\section{1) Lexical mixing}

At the lexical level, code mixing generally occurs when children do not remember the Tamil equivalent of that particular lexical item in English. The reason could be that the children have been learning some words mostly in English. It could be that they have been listening to their family members using those words only. Words like bus, fan, door, have become a part of the language repertoire of everybody. Nouns and verbs are preferred more while code mixing. Adjectives, adverbs and conjunctions are also used by children when they code mix.

- Intha flower romba beautifulla irrukku.

- Tortoise slowa nadanthu pochu.

- Rabbit tree keela thungiduchu.

- Tired aaicha so thungichu.

The above examples are from the speech samples of the students. The speech samples also showed that the students used Tamil as the matrix language and English words were embedded into it. Though English and Tamil have different word order (Tamil SOV and English SVO) the code mixing was perfectly done without any hesitation. The insertion of English words was neither artificial nor deliberate. The children did not make grammatical errors in the code mixed sentences. The sentences fully followed the Tamil grammatical structure and English words were infused in it. Code mixing was not found to be deliberate or unnatural.

\section{2) Phonological mixing}

If two languages interact with one another, it is inevitable that each of them influences the pronunciation of the other. The mixing of foreign words always entails their phonetic modification. The study showed that certain phonological modifications do happen when the two languages are mixed. The English words take some phonological features of Tamil. The mix of Tamil phonological features with English is obviously observed in the speech of Tamil medium educated students. In the students who are from English medium and who have fairly high degree of exposure to English words do not take the Tamil phonological features. For example, in picture identification task some children uttered the English words in the phonological pattern of Tamil. Like the words ball, bus etc. are uttered as ball $u$, car $u$, dooru, fan $u$, hen $u$.
- ball $+u=$ baal $u$
- $C a r+u=$ carru
- $d o o r+u=$ door $u$
- $f a n+u=$ fan $u$
- hen $+u=$ hen $u$

The $/ u /$ insertion is a part of Tamil phonology. English words are pronounced with the phonology of Tamil.

\section{B. Attitude}

Language has more functions than the single role of imparting facts. It carries with it affective values such as group identity and solidarity. A speaker may associate specific varieties of speech with positive or negative emotional values. The frequency of code mixing of bilinguals depends on whether the society considers code mixing positively or negatively. Negative attitude towards code mixing is not found among children. Children are not aware of the status of languages and do not develop special attitude towards it. Adults prefer to use English as it makes them feel 'modern'. Unlike adults, the use of English by children is not because of its 'prestige' status. There is no positive or negative attitude towards the use of English. Code mixing is because of simultaneous acquisition of Tamil and English. The general attitude in India for code mixing is not negative. The code mixing language behavior of children is not viewed as a negative behavior by them and their parents.

Annamalai [11] states that mixing is marked by the characteristics that no new grammar is created beyond the grammars of the two languages involved, one of which is glued to the other without changing it, and that the mixed code is not a determinant and is created anew by each speaker in each speech act and is not transmitted across generations. To prove the statement of Annamalai the code mixing samples of the children showed that no two children code mixed in the same style. Two children even when they narrated the same story did not code mix in the same manner.

\section{SOURCES OF EXPOSURE TO ENGLISH}

\section{A. Parent's Language}

Children are born with the capacity to acquire the language of the environment [12]. Several studies have proved that the quantity of language input is related to the language output of the children. The length of exposure and the quantity of exposure of English makes the children use English words frequently in their conversation. Parent's frequency of using 
English in a Tamil conversation was analyzed as that would throw light on the way their children used language.

Most of the parents stated that they used mixed language with their children during all their conversations. Mixing of English was inevitable for 53 percent of the parents as they had their education from English medium schools and communicated frequently in English with their colleagues and friends and also at home. 57 percent parents reported that they would borrow a word from English when they were not sure of the word in Tamil. 45 percent parents reported that they switched to English when there was no translation or a poor translation of the word in Tamil, and when the word was hard to pronounce in Tamil $(22 \%)$. They also were of the view that speaking to children in English will improve their language skills and it will help them in their future. In India English is looked upon as a language of progress.

\section{B. Schooling/Education}

Exposure to English comes largely from schooling. English medium students have a higher exposure to English than those from Tamil medium schools. Students become proficient in second language skills when schooled in English. The teaching of English is on the increase throughout the country. There is a rapidly increasing growth of English medium private schools. Koul states that these schools cater to the needs of the rising middle class which has understood the importance of English [13]. The language use of teachers is one of the second most important sources of exposure to English mentioned by the children.

Students who study in English medium have a fairly good exposure to English as most of the subjects are taught in English. The teachers teach and interact with students in English and insist that the students communicate with each other only in English. This increases the exposure of English and hence the students tend to code mix with English.

Students from Tamil medium schools have comparatively lesser exposure to English. The children from Tamil medium do not speak much in English. Parents of students from Tamil medium school are not much educated and do not speak English at home. So the students from Tamil medium have limited exposure to English. The students are not forced to speak in English. Hence the percentage of use of English in Tamil is comparatively lesser. Therefore code mixing is related to the exposure of English through education.

\section{Media}

The sources of exposure to English include movies, television, and radio. The media in Tamilnadu extensively uses English in almost all the programmes. The audience can easily learn English words and phrases from Tamil films, as well as radio and television programmes. The children watch television programmes which also use lot of English. In television and radio, the masters of ceremonies (emcee) of most of the programmes use a lot of English or mixed form in their shows. The exposure through media in different forms provides the children more contact with English. The English exposure through the media also facilitates learning English and hence gets integrated in Tamil speech.

As for the reading habits, some students reported that they did read English books, magazines and comics apart from their school text books. This adds to their additional vocabulary of English words. These words stay in their memory and get incorporated in the language that they speak.

\section{CONCLUSION}

The current study demonstrates that language mixing is a common behavior among bilingual children. The language mixing parents of bilingual children provides evidence of an association of higher rate of code mixing among children too.

Bilingualism is present in practically every country of the world, in all classes of society, and in all age groups [14]. This study focused on the language behavior of bilingual children who use code mixing as a communicative strategy. The bilingual children are able to communicate using the two languages, Tamil and English, in a meaningful way. Hence they can be considered as good bilinguals.

Parental language mixing plays a vital and influential role in the way the child acquires language. Other sources of exposure also play a major role in the language acquisition and language use of the children. The children start picking up words from their parents' conversation, from teachers and friends in school and also from television. Bilingual children are seen to code mix more than their parents.

Though children are unaware of the prestige status of English, parents feel that mixing with English and speaking in English is essential for the progress of the child. The parents' attitude towards language mixing is very positive. They feel that language mixing is a step to achieving fluency in English. About the mother tongue fluency parents seem to be less worried. Parents insist that children call them 'mummy' and 'daddy' instead of amma and appa.

Children are exposed to two languages at early age, they grow up in bilingual environment and hence they code mix to a larger extent. Children growing up with two languages will speak the two languages with ease. Their mixing patterns are also same as that of adults. But when one language dominates the other there is a probability that the language that is used less will not be spoken. The new generation is learning a mixed language. Will the language purity not be affected? The children speak a mixed tongue and this will be passed on to the generation to come. This might lead to a consequence where many Tamil words will be forgotten. Is this a healthy trend? Language contact, language change and variation is taking place at a rapid speed. The kind of language change and variation that is found in the speech of the next generation will be an interesting area of research.

\section{ACKNOWLEDGMENT}

The data reported in this paper were collected for a minor research project (Bilingual Language Behaviour) funded by the University Grants Commission of India (2012-14).

\section{REFERENCES}

[1] K. Krishnasamy, "Code mixing Tamil and English: a study of language use by college students in Tamilnadu," PhD thesis, Indian Institute of Technology, Madras: Chennai, 2008.

[2] S. Poplack, "Sometimes I'll start a sentence in Spanish y Termino en Español: toward a typology of Codeswitching," Linguistics, vol. 18, pp. 581-618, 1980. 
[3] F. Grosjean, "The bilingual's language modes," in One Mind, Two Languages: Bilingual Language Processing, J. L. Nicol ed., pp.1-22. Malden, MA: Blackwell Publishing, 2001.

[4] S. C. Chaudhary, "Knowledge of language and the multilingual mind," Language Sciences, vol. 20, no. 2, pp. 201-204, 1998.

[5] N. Chomsky, On Nature and Language, Cambridge University Press, the Edinburgh Building, Cambridge UK, 2003.

[6] R. C. Major, "Phonological differentiation of a bilingual child," Ohio State University Working papers in Linguistics, vol. 22, pp. 88-122.

[7] E. Lieven, "Bilingual language acquisition-commentary on Sebastian-gales," Human Development, vol. 53, pp. 256-263.

[8] M. Paradis, A Neurolinguistic Theory of Bilingualism, Amsterdam: John Benjamins, 2004.

[9] E. Thordardottir, "The relationship between bilingual exposure and vocabulary development," International Journal of Bilingualism, vol.15, no. 4, pp.426-445, 2011.

[10] E. Perecman, "Spontaneous translation and language mixing in a polyglot aphasic," Brain and Language, vol. 23, pp. 43-63, 1984.

[11] E. Annamalai, "The language factor in code mixing," International Journal of Sociology, vol. 75, pp. 47-54, 1989.

[12] K. B. Heinlein, "Parental language mixing: its measurement and the relation of mixed input to young bilingual children's vocabulary size," Bilingualism: Language and Cognition, 2012.
[13] O. N. Koul, "Language, education and communication," Indian Institute of Language Studies, Delhi, 2005.

[14] F. Grosjean, Life with Two Languages: An Introduction to Bilingualism, Cambridge, MA: Harvard University Press, 1982.

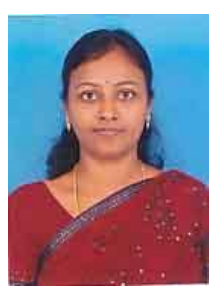

Kanthimathi Krishnasamy was born in South India She finished schooling from Kendriya Vidyalaya and completed post graduation in English from Madras University. She did $\mathrm{PhD}$ in linguistics from Indian Institute of Technology, Madras. Currently she teaches in a Women's College in Tamilnadu.

She has published research papers in International Journals of repute like English Today, International Journal of theoretical linguistics and Journal of Applied Linguistics. She has presented papers in various national and international conferences. She was presented the solidarity award to participate in the 15 th world congress of applied linguistics. Her research interests are English in India, Bi and multi-lingualism, Code mixing and Tanglish. Dr. Krishnasamy is a member of ELTAI and linguistics society of India. 